\title{
IMPROVEMENT OF DRIFT CALCULATION IN MOTHY OPERATIONAL OIL SPILL PREDICTION SYSTEM
}

\author{
Pierre Daniel, Fabien Marty, and Patrick Josse \\ Météo-France, DPrévi/Mar, 42 avenue Coriolis, \\ 31057 Toulouse Cedex - France \\ Chafih Skandrani and Rachid Benshila \\ Cedre, Rue Alain Colas - BP 20413 \\ 29604 Brest cedex - France
}

\begin{abstract}
MOTHY (Modèle Océanique de Transport d'Hydrocarbures) is a pollutant drift model, developed and operated by Météo-France. MOTHY includes hydrodynamic coastal ocean modelling and real time atmospheric forcing from a global meteorological model. Pollutants can be oil or floating objects. To improve forecasts on the Mediterranean Sea, several methods were tested to inject large scale currents (permanent part) into the MOTHY system. The best results were obtained with monthly means of currents at 5 meters (from Mercator system). The addition of altimetric corrections improved the results. In addition the impact of wave (or swell) current, which is usually neglected in such models, is investigated. The literature has surprisingly little to say on the topic of wave-driven surface oil slicks. Earlier review on oil spill transport modelling includes wave driven transport among potential advection mechanisms. The discussion of wave-induced advection (mass transport) adopts a Lagrangian framework, focusing on the analyses of Stokes and Longuet-Higgins for the vertical profile of the Lagrangian velocity beneath waves. In our work, the action of a vertical shear due to waves is accounted for by including the Stokes drift due to weakly non linear waves. We evaluate this term and compare with observations of Erika pollution incident.
\end{abstract}

\section{Discussion}

\section{1 - Introduction}

Météo-France has national and international responsibilities to agencies fighting marine oil pollution. Météo-France is in charge of spill drift predictions within the spill response plan POLMARMER in case of a threat for the French coastline. At an international level, Météo-France can intervene within the Marine Pollution Emergency Response Support System (MPERSS) for the high seas. MPERSS is a system co-ordinated by the World Meteorological Organisation (WMO). Its primary objective is to provide marine meteorological support for marine pollution emergency response operations on the high seas. The oceans and seas are divided into areas for which national Meteorological Services assume responsibility. Météo-France is Area Meteorological Co-ordinator or supporting service for the eastern part of North Atlantic ocean and also for the Mediterranean Sea.
Météo-France developed a pollutant drift model named MOTHY (Daniel, 1996). The model is operational and can be used round the clock for oil spills or drifting objects. MOTHY is an integrated system that includes hydrodynamic coastal ocean modelling and real time atmospheric forcing from a global or limited area model. The hydrodynamic coastal oceans is linked to an oil spill model, where oil slick is considered as a distribution of independent droplets. These droplets move with shear current, turbulent diffusion and buoyancy. New developments, exercises and training are jointly conducted with CEDRE (Centre de documentation de recherche et d'expérimentations sur les pollutions accidentelles des eaux). MOTHY correctly predicted the drift of the oil during Erika crisis (December 1999) in the Bay of Biscay (Daniel, 2001).

\section{2 - Large scale currents}

The present work focuses on evaluating the effects of large scale currents and comparing different methods to represent them in the MOTHY system. This effect is investigated in the Western part of the Mediterranean Sea where such currents are significant.

We have mainly used two actual pollution cases, for which observations are available: the accidents of the Haven (1991) and the Lyria (1993).

The Cypriot tanker Haven, a 109.700 tonnes - 313mt. long oil tanker, caught fire and suffered a series of explosions on the 11th April 1991, while at anchor seven miles off the coast of Genoa. The vessel was carrying approximately 144,000 tonnes of crude oil and it is estimated that over 50,000 tonnes of fresh and partially burnt oil were spilled into the sea. This caused the worst oil pollution incident ever in the Mediterranean Sea.

On August 1993, the 2,400-ton submarine Rubis collided with the 278,000 dwt 1,115-foot long oil super-tanker Lyria some 70 miles south of Toulon, tearing a hole in the tanker and causing an oil slick. The submarine damaged its bow. The spilled oil drifted for three weeks without reaching any coast.

Without permanent current, simulations show a drift which does not fit the observations (Figure 1).

Due to the lack of operational oceanography system on the Mediterranean Sea, the only available (total) currents are monthly or seasonal means (derived from climatology or produced by 
operational oceanography prototypes) at a given depth level. We studied a complete month of atmospheric forcing and its mean effect at the 5 meters level. It appeared that we can consider a monthly mean of total currents at 5 meters level as the permanent part which is missing.

2.1 Use of currents derived from climatology. The Mediterranean Oceanic Data Base (MODB) (Brankart, 1998) provides seasonal climatology of currents at 5 meters depth reconstructed from historical hydrological data. These data are available on a quarter degree grid mesh. With a simple addition of these currents to the final current given by MOTHY, we get results closer to the observations (figure 2).

2.2 Use of currents produced by operational oceanography prototypes. We used monthly means calculated on a $1 / 8$ degree grid mesh, with 3 years of simulation of the MERCATOR system (Madec, 1998). The MERCATOR mission seeks to develop and deploy a truly operational oceanography system capable of analyzing and predicting ocean conditions around the globe. This system will describe and predict ocean conditions over the whole ocean column continuously and in real time, at scales ranging from global phenomena to regional eddies.
The addition of the currents in the MOTHY system leads to better results than the MODB version, probably due to the better temporal and spatial resolution of these data (figure 3).

2.3 Use of currents anomalies derived from altimetry. From combined ERS-1 and TOPEX/POSEIDON altimetry data produced by the CLS Space Oceanography Division as part of the MAST-III MATER EC project (Ayoub, 1998), we calculated circulation anomalies. Then, we combined these anomalies with the yearly general circulation given by the MERCATOR system. This combination leads to the best results (figure 4).

\section{3 - Wave-driven currents}

The drift of floating pollutants such as oil slicks on the surface of the sea is due to a different physical process, among which wave drift is certainly significant. Existing practice in the hydrodynamic transport of surface oil slicks does not recognize the full potential of wave-driven transport. Common practice identifies tidal currents and wind drift as the major advective

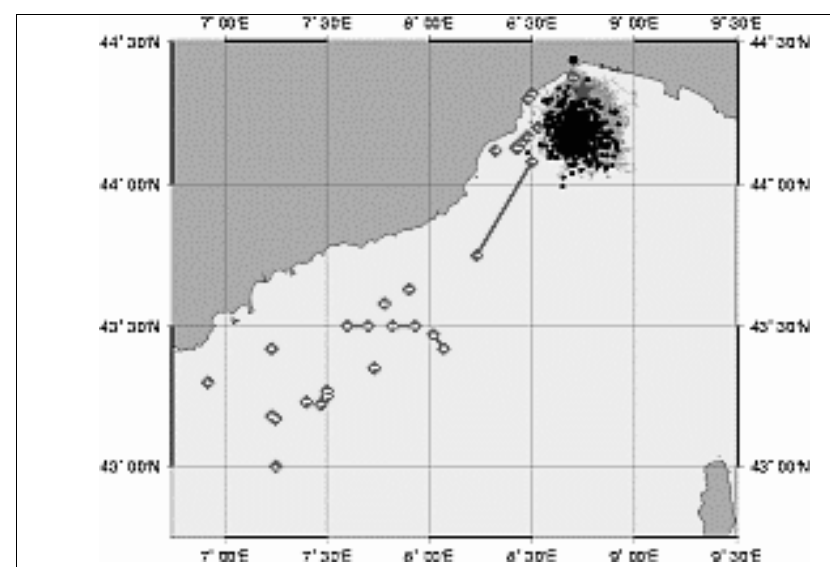

(a)

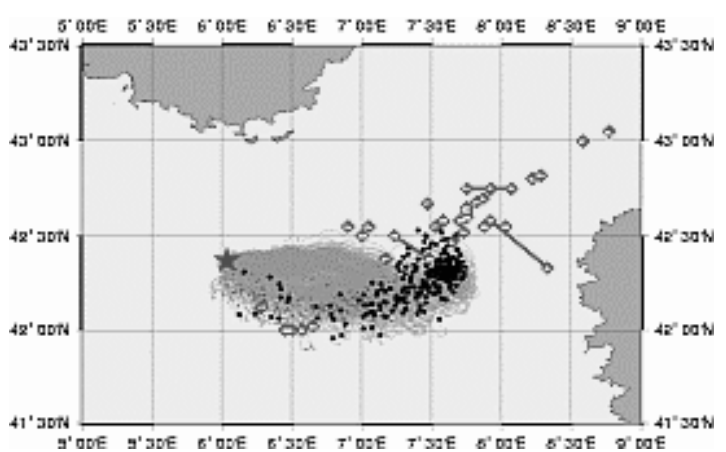

(b)

Figure 1. (a) Haven: 2 weeks forecast without permanent current. (b) Lyria: 3 weeks forecast without permanent current. The red star is the starting point, red diamonds are the observations, black spots figure the final position of the slick forecasted by MOTHY.

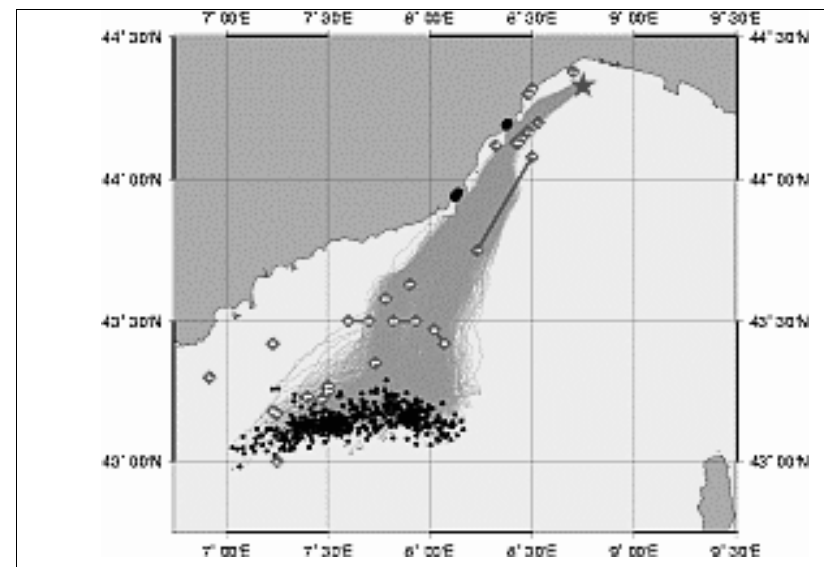

(a)

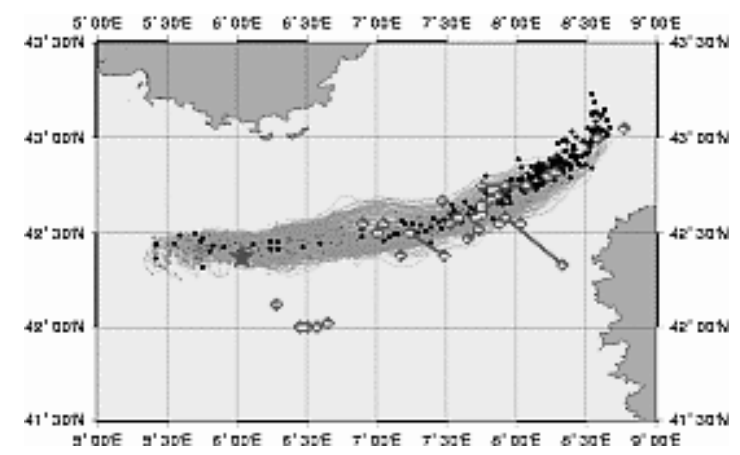

(b)

Figure 2. (a) Haven: 2 weeks forecast with seasonal current from MODB. (b) Lyria: 3 weeks forecast with seasonal current from MODB. The red star is the starting point, red diamonds are the observations, black spots figure the final position of the slick forecasted by MOTHY. 


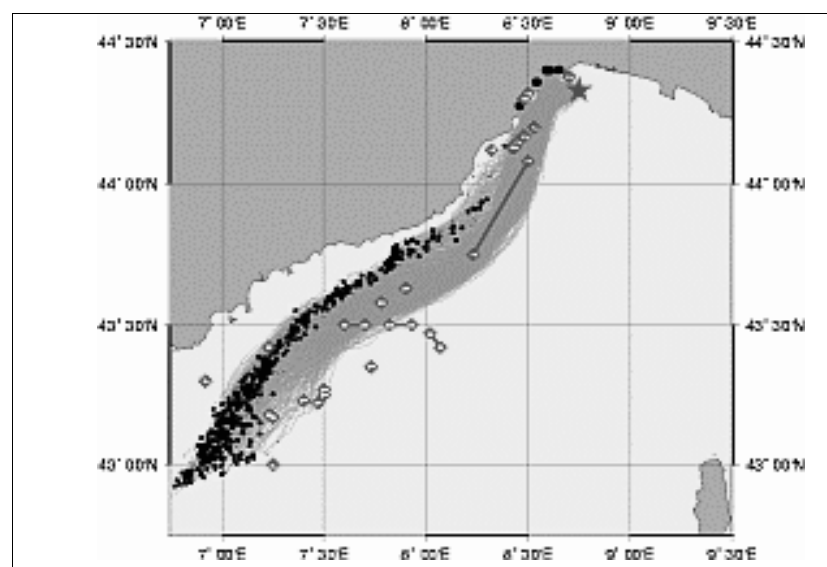

(a)

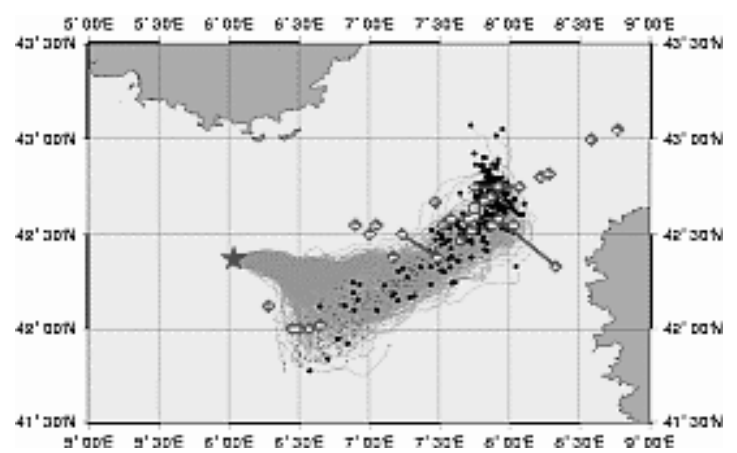

(b)

Figure 3. (a) Haven: 2 weeks forecast with monthly current from MERCATOR. (b) Lyria: 3 weeks forecast with monthly current from MERCATOR. The red star is the starting point, red diamonds are the observations, black spots figure the final position of the slick forecasted by MOTHY.

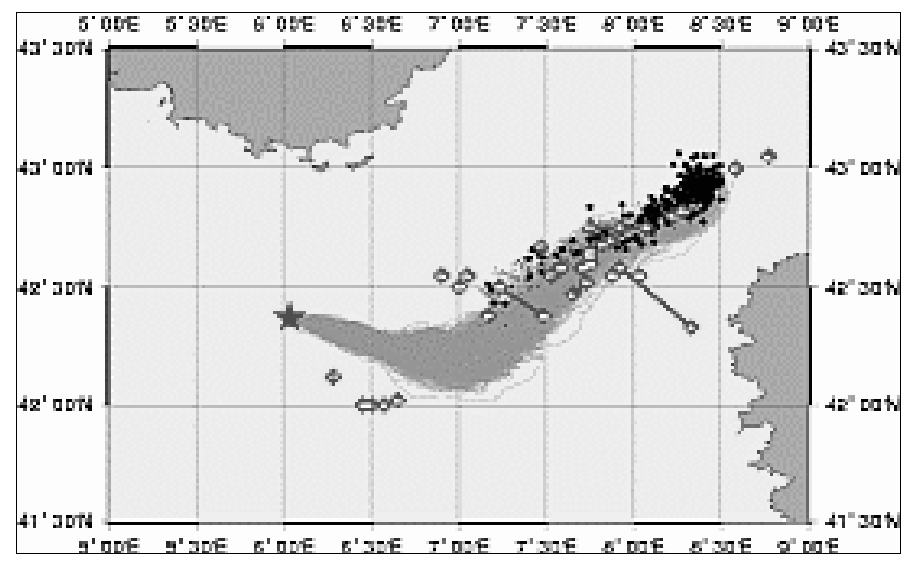

Figure 4. Lyria: 3 weeks forecast with monthly current from MERCATOR + current from altimetric anomalies. The red star is the starting point, red diamonds are the observations, black spots figure the final position of the slick forecasted by MOTHY.

transport mechanisms, yet surface wave drift velocities can be of comparable magnitude.

The current resulting as the consequence of the wave induced depth averaged mass transport is known as the "Stokes' drift", and its effects are very important when dealing with the movement of floating pollutants (e.g. oil slicks), and particularly so in the Mediterranean, where the tidal effects are often negligible. Under transient conditions the Stokes transport may become relatively more important because it can persist when a wind ceases to blow.

The literature has surprisingly little to say on the topic of wave-driven surface oil slicks. Earlier review on oil spill transport modeling includes wave driven transport among potential advection mechanisms. The discussion of wave-induced advection (mass transport) adopts a Lagrangian framework, focusing on the analyses of Stokes (1847) and Longuet-Higgins (1953) for the vertical profile of the Lagrangian velocity beneath waves. But, the scientific literature on drift and drift-related phenomena is of course very rich; we shall thus very quickly review only the papers which we consider to be relevant to the results deal with in this paper.

After Stokes' original work in the last century, the milestone of theoretical research in the field of wave drift is probably Longuet-
Higgins' [1953] classical paper which is of special interest when dealing with shallow waves, where the effects of viscosity are important. However, the results by Russel and Osorio [1957] as reported by Stolzenbach et al. [1977] and by Dyke and Barstow [1981] can be used to assess the acceptability of non viscous theories in the context of our work, which only deals with deep water waves.

As, it was reported recently by Giarrusso et al. [2001], sometimes the wave drift effect is considered in connection with the current advection and the wave induced depth averaged mass transport; this approach fails to take into account that an oil slick, like any floating object moves with the upper water layer, whose velocity is far bigger than the average. Besides, as Sobey and Barker [1997] pointed out, at least in near shore areas, the surface drift is directed towards the coast while the underlying currents go in different directions. The work presented by the first authors, concerned the effects of wave drift on the dispersion of floating pollutants. The second authors, investigated the potential of surface gravity waves to transport a surface oil spill in coastal waters.

The procedure we present in the following is based on making use of simulation of wave drift with Météo-France wave model data, VAG [2000]. 
In our work, the action of a vertical shear due to waves is accounted for by including the second approximation Stokes drift due to weakly non linear waves as already used by Elliot [1986] in his study on the north sea. In a first time, we estimate that is a first approach in introducing wave effect in MOTHY drift model. Furthermore, in a second time this approach will be improved, taking into account the operational constraints. Through this approach the wave data can be easily employed in our simulation.

3.1 Procedure. In progressive gravity waves of very small amplitude it is well known that the orbits of the particles are either elliptical or circular (see figure 5). In steep waves, however, the orbits become quite distorted (trajectories are not closed), as is shown (figure 6) by the existence of a mean horizontal drift or mass-transport in irrotational waves (Stokes 1847, 1880). Floating oil droplet is subjected to the movement caused by the orbital motion of water particles. ${ }^{2}$

Using a Lagrangian description of motion, the action of vertical shear due to waves is accounted for by including the Stokes drift (second order effect in irrotational flow) due to weakly nonlinear waves:

$$
U(z)=\omega \cdot k \cdot a^{2} \cdot \frac{\cosh (2 \cdot k \cdot(h-z))}{2 \cdot \sinh ^{2}(k \cdot h)}+C
$$

Where $a$ is the wave amplitude, $h$ is the water depth, $z$ depth beneath the surface. The wave circular frequency $\omega=2 \pi / T$ and the wave number $k=2 \pi / L$ for waves of period $T$ and wavelength $L$. The wave parameters are estimated from the Météo-France wave-model database (Direction of swell, swell period $T_{s}$ and swell significant wave height $H_{s}$ ) as $\omega_{s}=2 \pi / T_{s}$ and $a=H_{s} / 2 . L$ being calculated from the dispersion relation: for deep water waves (in open sea): $L \approx 1.56 T_{s}^{2}$ with $h>L / 2$ and, for finite depth or shallow waves (near the coast): $L \approx T \sqrt{ } g h$ with $h<L / 20, g$ is the gravity acceleration. Like in Elliot[1986], the depth independent term $C$, is neglected since it is likely to be small according to our study which only deals with deep water waves $(k h>>1)$. Wave current $\mathrm{U}(\mathrm{z})$ is added to the wind and tide currents for each droplet at its depth $\mathrm{z}$ beneath the surface.

3.2 Application and results. In this section, we'll illustrate the impact of wave drift on oil slick. We chose the case related to Erika accident, on $12^{\text {th }}$ December 1999. In this simulation, we need wave parameters (Direction of swell, wave period $T_{s}$ and significant wave height $H_{s}$ ). They are interpolated, both in space and time, to the MOTHY grid mesh using bilinear interpolation. Model mesh is fixed with a $5^{\prime}$ resolution. Time step is 15 seconds.

Figure 7, shows 2 weeks simulation of oil drifting. The effect of swell produces a shift towards the east which is less consistent with the observations at sea. But impacted coastline is nearly the same.

On figure 8, the drift of only one droplet is represented. It shows more clearly the shift towards the east. With tide currents, we can see small loops. But the drift is not significantly different.

Figure 9 shows the differences in the intensity of wind current, tide current and wave current. Tide currents become more significant near the coast. Wave current are smaller but with a nearly constant direction from the west.

3.3 Discussion. These preliminary results shows that the wave effect is significant but coherence with the observations could not be fully established. A limitation on the application of Stokes drift velocity equation to the ocean is that for fully developed seas wave breaking occurs, and this violates conditions of applicability under which this equation (irrotational theory) was derived. But, we can think that viscosity of oil pollutant film will damp the

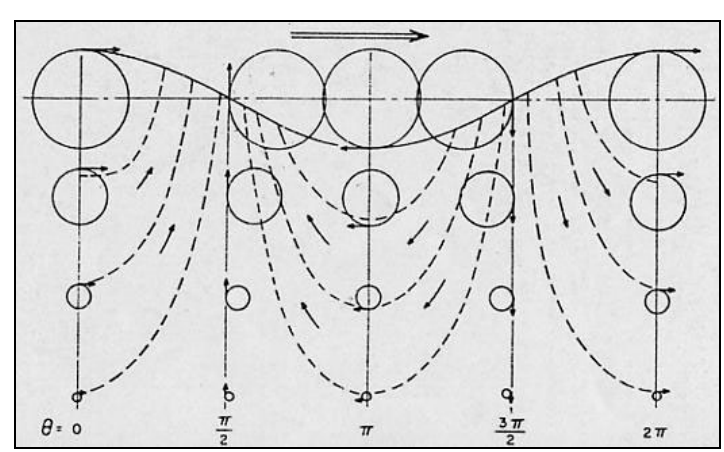

(a)

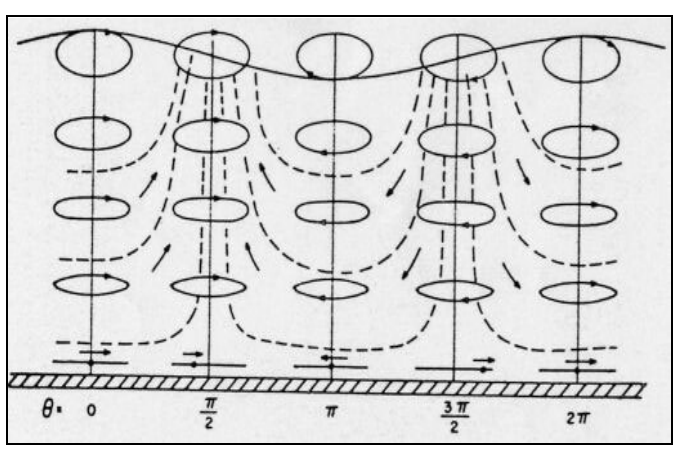

(b)

Figure 5. (a) Qualitative depiction of orbits, orbital velocities and stream lines in deep water waves. (b) Representation trajectories and stream lines for shallow water wave.

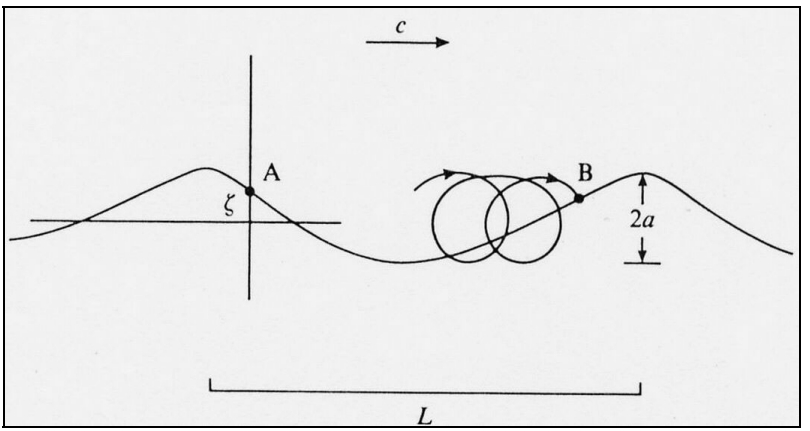


Figure 6. Measurement of surface waves with a fixed staff A, and with a free-floating buoy B (from Longuet-Higgins, 1986).

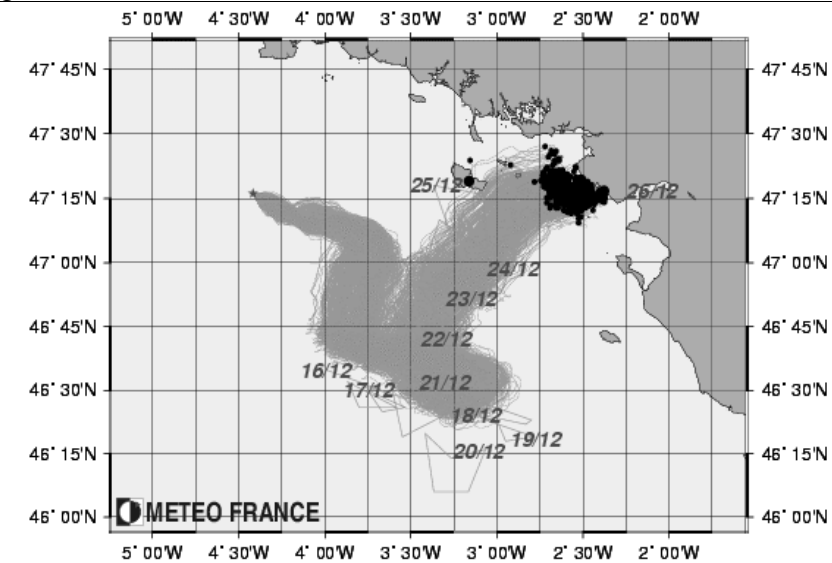

(a)

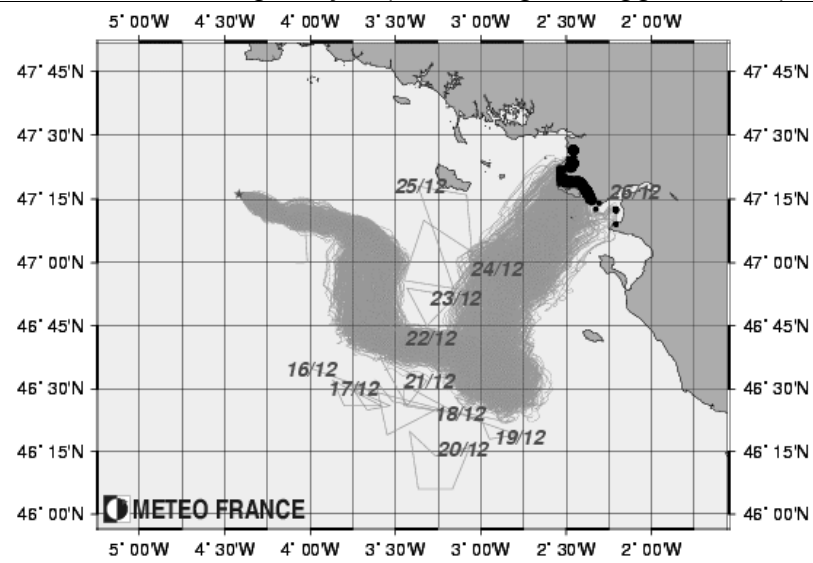

(b)

Figure 7. Drift of slick on the 12/12/99 Erika accident. (a) operational MOTHY. (b) MOTHY with swell effect. The green lines correspond to slick observed with date. The gray lines illustrate the trajectories.

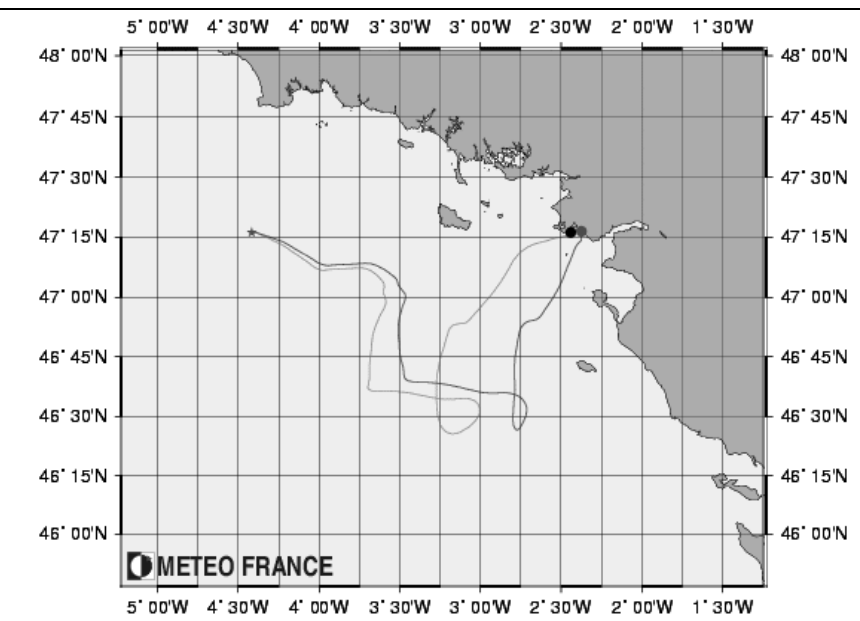

(a)

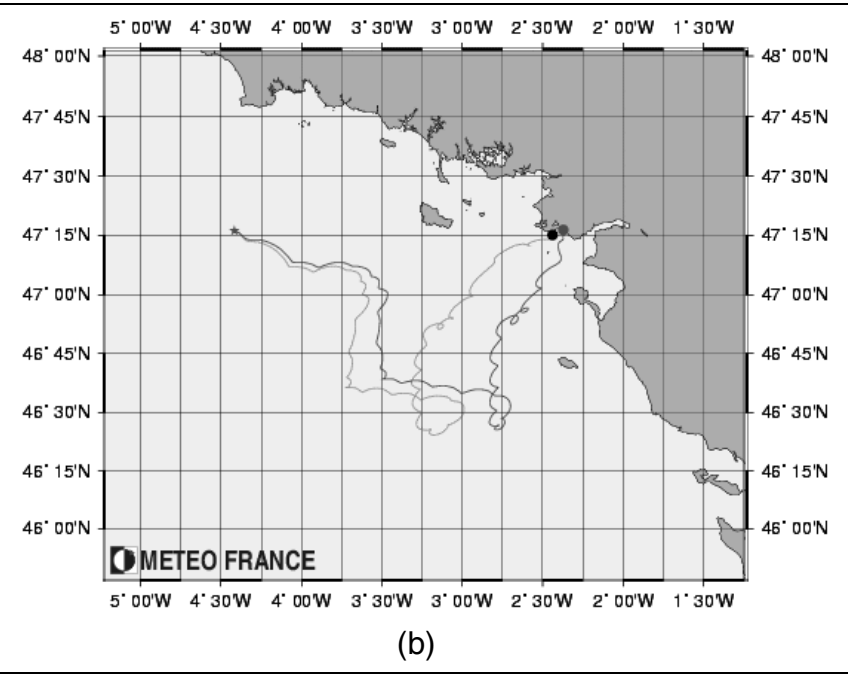

(b)

Figure 8. Drift of one droplet. Gray line: operational (without Stokes drift). Red line: with wave Stokes drift. (a) Without tidal effect. (b) With tidal effect.

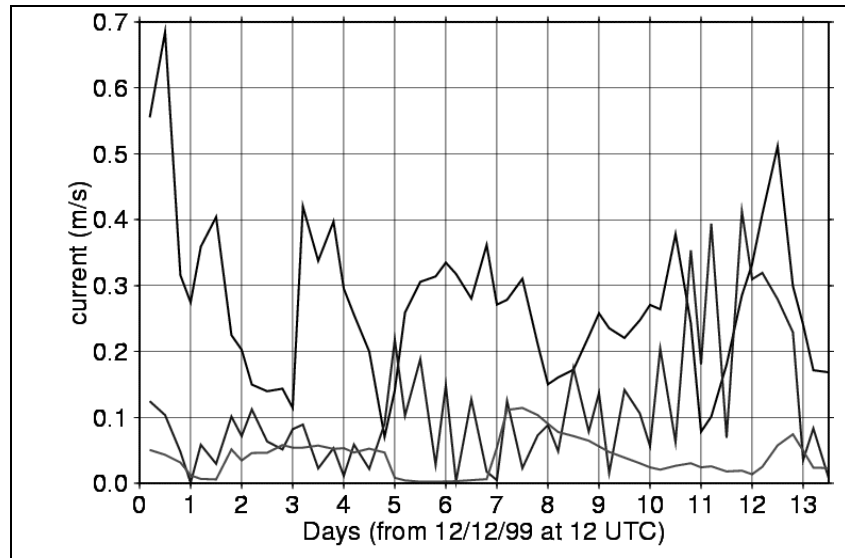

(a)

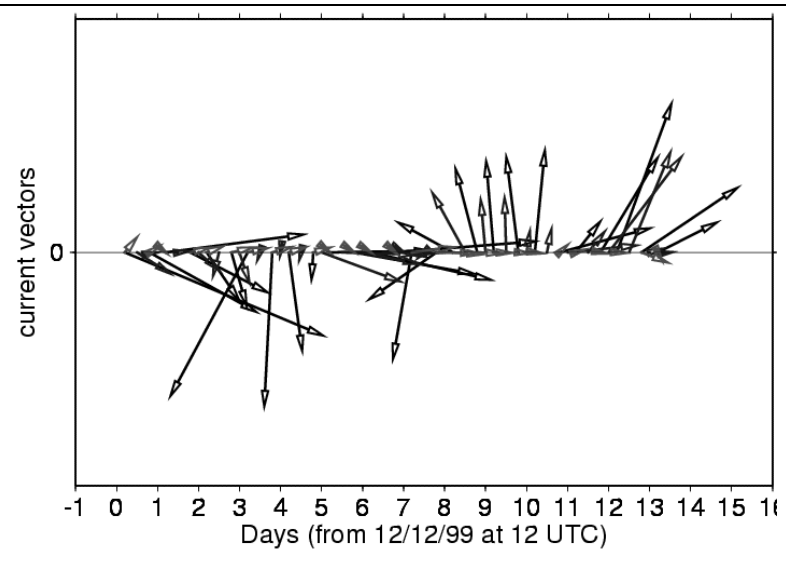

(b)

Figure 9. (a) Intensity of current. Black line: wind-induced current. Blue line: tidal current. Red line: Stokes current. (b) vectors of current. Black arrow: wind. Blue arrow: tidal. Red arrow: wave 
waves and attenuate the breaking. Near the coast, for finite depth, it seems that from the syntheses of the rich literature on the problem of mass-transport, the Stokes solution may be considered a good approximation to the motion for a brief period after a wave runs into still water. However, after a short time, vorticity generated at the boundaries diffuses and is convected inward, so that, except for the initial period, the second-order viscous solution (Longuet-Higgins, 1953) will be suitable.

\section{Conclusions}

Monthly current means from Mercator ocean model lead to consistent results with the observations. The use of altimetric data still improves the results. That is encouraging for a future use of currents from operational ocean models which will assimilate this type of data. Preliminary results show a significant effect of the wave currents.

\section{Biography}

Pierre Daniel has been a $R \& D$ engineer in coastal ocean modelling since 1991. He is in charge of oil spill drift modelling at Météo-France. $\mathrm{He}$ is rapporteur on Marine Pollution Emergency Response Support System within the World Meteorological Organisation.

Patrick Josse has a PhD in Physical Oceanography and is deputy director in charge of $\mathrm{R} \& \mathrm{D}$ activities at the Marine Forecast Section of Météo-France.

Chafih Skandrani has a $\mathrm{PhD}$ in Fluid Mechanics. R\&D activities related to waves physics.

\section{References}

1. Ayoub N., P-Y Le Traon and P. De Mey, A description of the Mediterranean surface variable circulation from combined ERS-1 and TOPEX/POSEIDON altimetric data, Journal of Marine Systems 18 (1-3), pp. 3-40, 1998.

2. Brankart J.M. and P. Brasseur, The general circulation in the Mediterranean Sea: a climatological approach, Journal of Marine Systems 18 (1-3), pp. 41-70, 1998.

3. Daniel P., Operational forecasting of oil spill drift at Météo-France. Spill Science \& Technology Bulletin. Vol. 3, $\mathrm{N}^{\circ} 1 / 2$, pp. 53-64, 1996.

4. Daniel P., P. Josse, P. Dandin, V. Gouriou, M. Marchand, C. Tiercelin. Forecasting the Erika oil spills, Proceedings of the 2001 International Oil Spill Conference, American Petroleum Institute, Washington, D.C, pp 649-655, 2001.

5. Elliot, A., 1986:Shear Diffusion and the Spread of Oil in the Surface Layers of the North Sea. Dt. Hydrogr. Z. 39, 113-137.

6. Fradon, B., Hauser, D and Lefevre, J.M., 2000: Comparison study of a second-generation and of a thirdgeneration wave prediction model in the context of the semaphore experiment. J. Of Atmosph. And Ocean. Tech. Vol. 17, $\mathrm{N}^{\circ} .2$ 197-214.

7. Giarrusso, C.C., Pugliese Carratelli, E., Spulsi, G., 2001: On the effects of wave drift on the dispersion of floating pollutants. Ocean Engineering. 28, 1339-1348

8. Ianniello, J. P. and Garvine. R. W., 1975: Stokes transport by gravity waves for application to circulation models. $J$. Physic. Oceano. 5, 47-50.

9. Kenyon, K. E., 1969: Stokes drift for random gravity waves. J. Geophys. Res., 74 (28), 6991-6994.

10. Kenyon, K. E., 1970: Stokes transport. J. Geophys. Res., 75 (6), 1133-1135.

11. Longuet-Higgins, M.S., 1953: Mass transport in water waves. Phil. Trans. Roy. Soc., A245, 535-581.

12. Longuet-Higgins, M.S., 1986: Eulerian and Lagrangian aspects of surface waves. J. Fluid. Mech. vol. 173, 683707.

13. Madec G., Delecluse P., Imbard M., Lévy C. OPA8.1 ocean general circulation model reference manual, Notes du pôle de modélisation IPSL, 11, 1998.

14. Piro, G., Pugliese Carratelli, E., Sansone, E., 1992: Stokes drift effects computed from measured wave data. In: Partridge, P. W. (Ed.) Computer Modelling of Seas and Coastal Regions. CMP, Southampton, UK. 21-32.

15. Russel, R. C. H. and J. D. C. Osorio, 1975: An experimental investigation of drift profiles in a closed channel. Proc. $6^{\text {th }}$. Conf. Coast. Engr. (Miami), ASCE, 171-193, 158.

16. Sobey, R. J., Barker, C. H., 1997: Wave-driven transport of surface oil. J. of Costal Research 13 (2), 490-496.

17. Stokes, G. G., 1847: On the theory of oscillatory waves. Trans. Cambridge Phil. Soc., 8, 441-455.

18. Stokes, G. G., 1880: Mathematical and Physical Papers, Vol. I. Cambridge: University Press.

19. Stolzenbach, K. D., O. S. Madsen, E. E. Adams, A. M. Pollak and C. K. Cooper, 1977: Review and evaluation of basic techniques for predicting the behaviour of surface oil slicks. Rep. Massachusetts Inst. Technol., Dep. Civil Engng. $\mathrm{N}^{\circ}$. 222, 315 pp. [unpubl. Manuscript]. 